\title{
Diaphragm and weaning from mechanical ventilation: anticipation and outcome
}

\author{
Rasha M. Abdelhafeez, Ahmed M. Abumossalam, Eman O. Arram, \\ Mohsen M. Elshafey, Mohammed E. Abushehata
}

\begin{abstract}
Background Determining the optimal moment to extubate a critically ill patient remains a challenge. The parameters of diaphragm sonography offer precious data in the evaluation and follow-up of critically ill patients on mechanical ventilation.
\end{abstract}

Aim To evaluate the diaphragm role in the weaning outcome through the following objectives: detect the association between ultrasonographic parameters of diaphragm [thickness, excursion, and velocity of contraction (slope)] and weaning outcome, success, or failure, in addition to evaluation of the weaning process by measuring the total duration of ventilation, weaning duration, ICU stay, and reventilation.

Patients and methods A longitudinal, observational, prospective study. The primary endpoint was weaning outcome (failed or successful), while the secondary endpoints included length of ICU stay, weaning duration, ventilation duration, presence or absence of complications, and mortality. It was conducted on 240 (138 men and 102 women) invasively mechanically ventilated patients aged between 20 and 78 years were chosen from our Respiratory ICU of Chest Department, Mansoura University Hospital.

Results There were statistically significant higher values of all sonographic measurements in the survived compared with

\section{Introduction}

Determining the optimal moment to extubate a critically ill patient remains a challenge. Premature removal of mechanical ventilation (MV) entails a high risk of weaning failure, prompting reintubation that exposes the patient to unnecessary hemodynamic and respiratory stress. Thus, both early and delayed weaning are associated with increased mortality, stay in the ICU, and economic cost [1].

The process of weaning from ventilatory support takes almost $40 \%$ of the time spent on a ventilator. Weaning indices such as spontaneous tidal volumes, minute ventilation, and rapid shallow breathing index (RSBI) have been used extensively in clinical practice for weaning purposes. These parameters measure the overall respiratory volumes produced by the muscles of breathing and do not take into account the independent contribution of the diaphragm which is a major determinant to delayed weaning, highlighting the significance of diaphragmatic assessment [2].

Assessment of respiratory muscles, particularly the diaphragm, is lacking in the daily practice of ICUs the died group $(P<0.001)$. There was statistically significantly higher sonographic diaphragmatic measurements in the successful group compared with the failed group $(P<0.001)$.

Conclusion The measurement of percent change of diaphragmatic thickness as well as excursion and slope could be applied in correlation more with weaning outcome with a sensitivity of $100 \%$ and specificity of $97.4 \%$.

Egypt J Bronchol 2019 13:489-497

C 2019 Egyptian Journal of Bronchology

Egyptian Journal of Bronchology 2019 13:489-497

Keywords: Acute Physiology and Chronic Health Evaluation score, diaphragmatic ultrasound, excursion, mechanical ventilation, thickness, weaning

Thoracic Medicine Department, Mansoura University Hospital, Mansoura, Egypt

Correspondence to Ahmed M. Abumossalam, Associate professor (MD) of Pulmonary and Critical Care Medicine, Department of Pulmonary and Critical Care Medicine, Faculty of Medicine, Mansoura University, Mansoura, 35516, Egypt. Tel: +20 100842 4320; fax: +2 050 2202834; e-mail: abumossalam79@yahoo.com

Received: 12 February 2019 Revised: 12 April 2019 Accepted: 22 May 2019 Published: 25 October 2019

despite the strong evidenced diaphragmatic dysfunction in ICU patients on MV [3].

Imaging plays an imperative role with clinical data in the evaluation and management of ICU patients [4], consequently ultrasound in ICUs is growing [5] due to safety, rapidity, easy carriage and hopeful outcome achieved for management [6]. Ultrasonography offers informations in real time about the organ's function and morphology as well as evaluation of the status of aeration of pulmonary parenchyma [7] and functional status of the diaphragm offering hints on the possibility of successful weaning [8].

Ultrasonography is an easy noninvasive technique to evaluate diaphragmatic movement characters such as force, amplitude, and speed of contraction (slope), particular outline of movement, and alterations in the thickness of diaphragm. The parameters of

This is an open access journal, and articles are distributed under the terms of the Creative Commons Attribution-NonCommercial-ShareAlike 4.0 License, which allows others to remix, tweak, and build upon the work non-commercially, as long as appropriate credit is given and the new creations are licensed under the identical terms. 
diaphragm sonography offer precious data in the evaluation and follow-up of critically ill patients on MV, and help to understand weaning failure [9].

\section{Aim}

The aim of our study is to evaluate the role of diaphragm in weaning outcome through the following objectives: Detect the association between ultrasonographic parameters of diaphragm [thickness, excursion and velocity of contraction (slope)] and weaning outcome, success, or failure, in addition to evaluation of the weaning process by measuring total duration of ventilation, weaning duration, ICU stay, and reventilation.

\section{Patients and methods \\ Patients}

Two hundred and forty (138 men 102 women) invasively $\mathrm{MV}$ patients aged between 20 and 78 years were chosen from our respiratory ICU of Chest Department, Mansoura University Hospital from April 2015 to May 2017.

Ventilators used were of event medical inspiration type; Event medical inspiration LS ventilator version 3.2.5 Event Medical Limited (Ireland). All patients were subjected to pressure-controlled ventilation with sedation with midazolam and possible muscle relaxation with atracurium for $24-48 \mathrm{~h}$ and were then subjected to intermittent mandatory ventilation (PSIMV) for 24-48 $\mathrm{h}$ followed by spontaneous mode (PSV) for 12-24h, then extubation if the patient did not improvewith subsequent failure. Spontaneous mode used was pressure support ventilation.

\section{Exclusion criteria}

(1) Age less than 18 years.

(2) MV due to:

(a) Before ICU admission cardiorespiratory arrest.

(b) Advanced pulmonary fibrosis.

(c) Pulmonary metastasis.

(d) Kyphoscoliosis.

(e) Neuromuscular disorders.

(3) Hepatosplenomegaly/tense ascites.

(4) Patients who died before third day of ventilation.

(5) Pregnancy more than 28 weeks.

\section{Study design}

A longitudinal, observational, and prospective study. The primary endpoint was weaning outcome (failed or successful), while the secondary endpoints included length of ICU stay, weaning duration, ventilation duration, and presence or absence of complications and mortality.

\section{Weaning outcome}

(1) Weaning success [10]:

(a) Simple weaning: weaning duration less than week and patient weaned successfully from the first weaning trial.

(b) Difficult weaning: weaning duration up to week and patient weaned successfully after three weaning trials.

(2) Weaning failure [6]:

Weaning failure was defined as one of the following:
(a) Nonscheduled extubation.
(b) Need for reintubation.
(c) Need for noninvasive positive pressure ventilation of the patient within $48 \mathrm{~h}$ after extubation.
(d) Delayed extubation.
(e) Tracheostomy.

\section{Patients and methods}

The study was conducted after prior approval from Mansoura Medical Research Ethics Committee and obtaining patient's relatives' written informed consent.

\section{For all patients, the following steps were done}

(1) Clinical evaluation with attention to age, sex, original disease, and cause of admission to respiratory ICU.

(2) Admission severity assessment by using Acute Physiology and Chronic Health Evaluation II (APACHE II) score.

(3) Daily weaning checklist parameters recording.

(4) Daily assessment for spontaneous breathing trail.

(5) Riker sedation/agitation scale recording: evaluating patient orientation and synchronization [11].

(6) Transthoracic echopulmonography at first day of $\mathrm{MV}$, at the start of weaning and just before extubation.

The ICU attendant physicians were blinded to the ultrasound result. Patients were managed and weaned according to our ICU protocol. On the first day of MV, all patients were on mandatory ventilation $(\mathrm{PC}, \mathrm{VC}$, PRVC). Patients were put on spontaneous mode when 
fulfilling the four weaning checklist criteria plus becoming afebrile $\left(\mathrm{T}<38 \mathrm{C}, 100.4^{\circ} \mathrm{F}\right)$.

Ultrasonographic examinations were carried out by two investigators using a portable ultrasonography (Mindray DP-2200; Shenzhen Lontek Electronic Technology Co., Limited, China) with $3.5-5 \mathrm{MHz}$ curved and $7-10 \mathrm{MHz}$ linear high-frequency probe transducers for adult. Ultrasonography was performed in supine position; using both motion (M) mode and two-dimensional brightness (B) mode, find the best approach and select the exploration line of each hemi-diaphragm. Liver was used as a window on right hemi-diaphragm, and the spleen was used on the left hemi-diaphragm.

\section{Right hemi-diaphragm ultrasonography}

The probe was placed between the midclavicular and anterior axillary lines, in the subcostal area, and directed medially, cranially, or dorsally, so that the ultrasound beam reached perpendicularly the posterior third of the right hemi-diaphragm (Fig. 1).

\section{Left hemi-diaphragm ultrasonography}

A subcostal or low intercostal probe position was chosen between the anterior and midaxillary lines to obtain the best imaging of the left hemi-diaphragm.

Multiple respiratory cycles of at least three cycles were examined and recorded and the average was taken. Every side measurements (right and left hemidiaphragms) were measured and calculated separately and then the average of measurements of the two sides was calculated.

\section{Statistical analysis}

The collected data were coded, processed, and analyzed using the statistical package for the social sciences (SPSS) version 15 for Windows (SPSS Inc., Chicago, Illinois, USA). Qualitative data were presented as number and percent. Comparison between groups was done by $\chi^{2}$-test, for example: comparison between different diaphragmatic functions in sonographic-based diaphragmatic function score. Quantitative data were tested for normality by the Kolmogorov-Smirnov test. Normally distributed data were presented as mean \pm SD. Student's $t$-test was used to compare between two groups, for example: comparison of sonographic diaphragmatic measurements in successful and failed groups just before extubation. $F$-test (one-way analysis of variance) was used to compare between more than two groups, for example: comparison of sonographic
Fig. 1

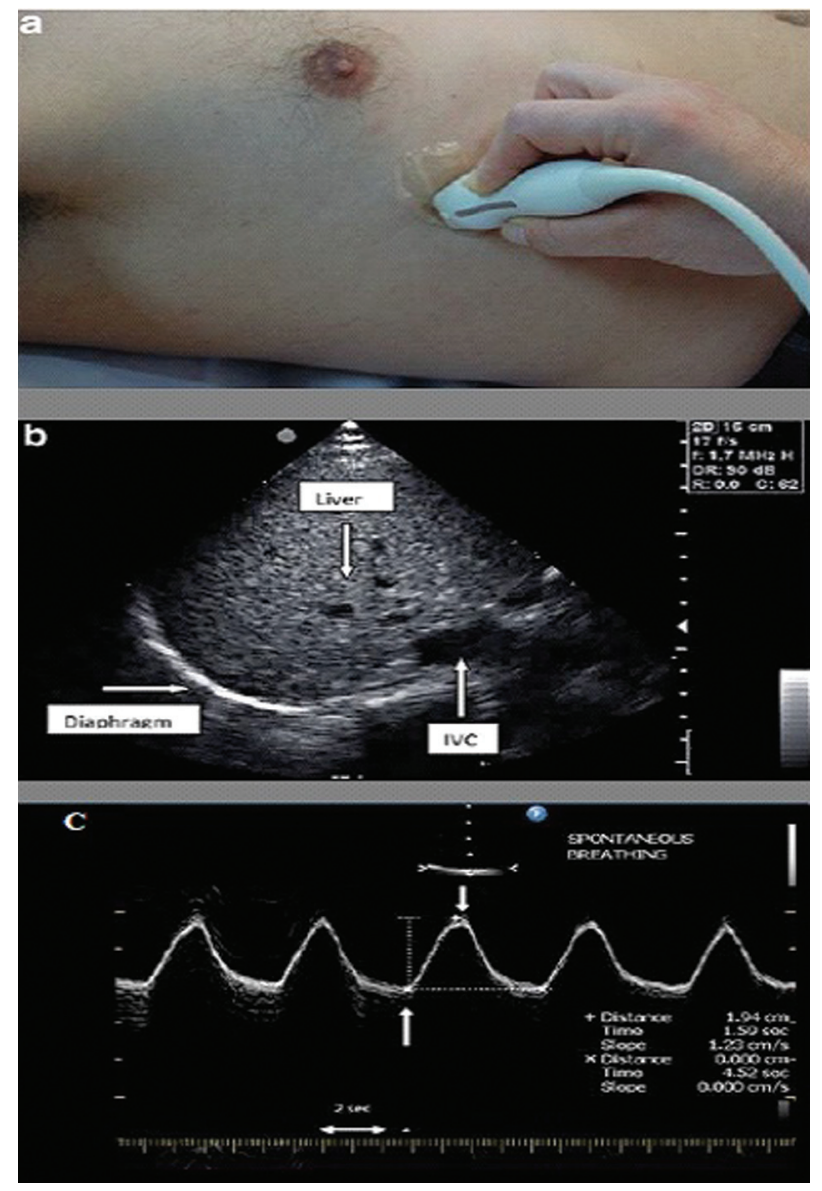

(a) Probe position for $\mathrm{B}$ and $\mathrm{M}$-mode diaphragmatic excursion measurements with $3.5-5 \mathrm{MHz}$ probe. (b) B-mode diaphragm sonography. The bright line reflects the diaphragm. (c) M-mode diaphragm sonography. Arrows indicate the beginning and the end of the diaphragmatic contraction.

diaphragmatic measurements in different weaning methods. $P$ value less than 0.05 was considered to be statistically significant. The receiver operating characteristic curve was used to determine the cutoff values of sonographic measurements [percent change in diaphragmatic thickness (tdi\%), excursion and slope] that predict weaning success.

\section{Results}

Twenty-seven patients from the 267 patients did not complete the study for being dead before the third day of ventilation. Two hundred and forty (138 men and 102 women) patients completed the study, their age ranged from 20 to 78 years. From the 240 patients, 117 had successfully weaned from which 111 patients were with simple weaning and six patients were with difficult weaning, and 123 patients had failed weaning from which 99 patients were with terminal extubation, 12 patients with reventilation, seven patients with delayed extubation, and five patients were with tracheostomy (Table 1). 
Pneumonia was the disease with the highest percentage in this study (47.5\%), followed by mixed diseases $(47.1 \%)$ and then chronic obstructive pulmonary disease (COPD) (27.1\%).

There was statistically significant higher APACHE II score $(P<0.001)$ (indicating more severity) in the failed compared with the successful group. Duration of ICU stay was statistically significantly higher in the successful group compared with the failed group $(P=0.001)$. Duration of using sedation per hour was

Table 1 Primary diagnosis of ventilated patients

\begin{tabular}{lc}
\hline & $N(\%)$ \\
\hline Pneumonia & $123(51.3)$ \\
ARDS & $16(6.7)$ \\
COPD & $65(27.1)$ \\
SDB & $31(13)$ \\
Bronchiactasis & $7(2.9)$ \\
Cavitary lesions & $6(2.5)$ \\
Alveolar hemorrhage & $4(1.7)$ \\
Lung cancer & $5(2.1)$ \\
Pulmonary embolism & $12(5.0)$ \\
Bronchial asthma & $2(0.8)$ \\
TB & $13(5.4)$ \\
DPLD & $9(3.7)$ \\
Combined pulmonary diseases & $113(47.1)$ \\
\hline
\end{tabular}

ARDS, acute respiratory distress syndrome; COPD, chronic obstructive pulmonary disease; DPLD, diffuse parenchymatous lung disease; SDB, sleep-disordered breathing; TB, tuberculosis. statistically significantly higher in the failed group (indicating prolonged mandatory ventilation) compared with the successful group $(P<0.001)$, while there were no statistical significance of weaning and ventilation duration (Table 2).

There was statistically significant higher APACHE II score (indicating more severity) in died compared with the survived group $(P<0.001)$. ICU stay duration was statistically significantly higher in the survived compared with the died group $(P=0.016)$. Duration of using sedation per hour was statistically significantly higher in the died compared with the survived group with $P$ value less than 0.001 , while there were no statistical significance of weaning duration and ventilation duration (Tables 3-5).

There were statistically significantly higher values of all sonographic measurements in the survived compared with the died group $(P<0.001)$. There was statistically significantly higher sonographic diaphragmatic measurements in the successful group compared with the failed group $(P<0.001$; Tables 6 and 7$)$.

\section{Discussion}

The appropriate timing of weaning from $\mathrm{MV}$ is fundamental in critically ill patients. Inappropriate

Table 2 Relation of Acute Physiology and Chronic Health Evaluation II score, ICU stay duration, weaning duration, ventilation duration, and duration of using sedation per hour to weaning outcome

\begin{tabular}{|c|c|c|c|c|c|c|}
\hline & \multicolumn{2}{|c|}{ Weaning outcome } & \multirow[t]{2}{*}{$P$} & \multirow[b]{2}{*}{ Survived $(N=141)$} & \multirow[b]{2}{*}{$\operatorname{Died}(N=99)$} & \multirow[t]{2}{*}{$P$} \\
\hline & Failed $(N=123)$ & Successful $(N=117)$ & & & & \\
\hline APACHE II score & $24.65 \pm 5.92$ & $15.19 \pm 5.49$ & $<0.001$ & $17.16 \pm 6.78$ & $24.13 \pm 6.29$ & $<0.001$ \\
\hline ICU stay duration & $5.77 \pm 2.90$ & $7.00 \pm 2.50$ & 0.001 & $6.73 \pm 2.52$ & $5.86 \pm 3.04$ & 0.016 \\
\hline Weaning duration & $3.65 \pm 2.09$ & $3.51 \pm 1.62$ & 0.593 & $3.52 \pm 1.65$ & $3.68 \pm 2.15$ & 0.593 \\
\hline Ventilation duration & $5.02 \pm 2.29$ & $5.11 \pm 2.44$ & 0.756 & $5.17 \pm 2.79$ & $4.99 \pm 2.35$ & 0.600 \\
\hline Duration of sedation $/ \mathrm{h}$ & $62.85 \pm 11.36$ & $30.37 \pm 11.08$ & $<0.001$ & $35.96 \pm 11.88$ & $62.75 \pm 10.87$ & $<0.001$ \\
\hline
\end{tabular}

APACHE II score: acute physiology and chronic health evaluation II score.

Table 3 Sonographic measurements during the course of ventilation

\begin{tabular}{lcc}
\hline & $N$ & Reange \\
\hline First day of ventilation & & \\
$\quad$ Percent change of diaphragmatic thickness & 240 & $17-76 \%$ \\
Diaphragmatic excursion & 240 & $0.89-2.50 \mathrm{~cm}$ \\
Diaphragmatic slope & 240 & $0.54-1.70 \mathrm{~cm} / \mathrm{s}$ \\
At the start of weaning & & $1.79 \pm 0.42$ \\
Percent change of diaphragmatic thickness & 235 & $26.0-76.05 \%$ \\
Diaphragmatic excursion & 235 & $0.90-2.54 \mathrm{~cm}$ \\
Diaphragmatic slope & 235 & $0.55-1.70 \mathrm{~cm} / \mathrm{s}$ \\
Just before extubation & & $1.12 \pm 0.67$ \\
Percent change of diaphragmatic thickness & 117 & $1.69 \pm 0.44$ \\
Diaphragmatic excursion & 117 & $31.39-76.05 \%$ \\
Diaphragmatic slope & 117 & $1.28-2.52 \mathrm{~cm}$ \\
\hline
\end{tabular}




\begin{tabular}{|c|c|c|c|}
\hline & \multicolumn{2}{|c|}{ Weaning outcome } & \multirow[t]{2}{*}{$P$} \\
\hline & Failed $(N=123)$ & Successful $(N=117)$ & \\
\hline \multicolumn{4}{|l|}{ First day of mechanical ventilation } \\
\hline Percent change of diaphragmatic thickness & $24.63 \pm 3.49$ & $40.36 \pm 10.64$ & $<0.001$ \\
\hline Diaphragmatic excursion & $1.40 \pm 0.18$ & $2.15 \pm 0.16$ & $<0.001$ \\
\hline Diaphragmatic slope & $0.79 \pm 0.44$ & $1.39 \pm 0.16$ & $<0.001$ \\
\hline \multicolumn{4}{|l|}{ At start of weaning } \\
\hline Percent change of diaphragmatic thickness & $22.47 \pm 4.53$ & $41.93 \pm 10.24$ & $<0.001$ \\
\hline Diaphragmatic excursion & $1.38 \pm 0.19$ & $2.19 \pm 0.17$ & $<0.001$ \\
\hline Diaphragmatic slope & $0.73 \pm 0.10$ & $1.41 \pm 0.15$ & $<0.001$ \\
\hline
\end{tabular}

There were statistically significant higher sonographic measurements in the successful group $(P<0.001)$ compared with the failed group.

Table 5 Relation of sonographic measurements to final outcome/weaning outcome just before extubation

\begin{tabular}{lccccc}
\hline & Survived $(N=141)$ & Died $(N=99)$ & $P$ & Failed $(N=123)$ & Successful $(N=117)$ \\
\hline Percent change of diaphragmatic thickness & $38.57 \pm 11.91$ & $22.32 \pm 4.61$ & $<0.001$ & $22.47 \pm 4.53$ \\
Diaphragmatic excursion & $2.04 \pm 0.37$ & $1.39 \pm 0.18$ & $<0.001$ & $1.38 \pm 0.19$ & $21.93 \pm 10.24$ \\
Diaphragmatic slope & $1.29 \pm 0.30$ & $0.73 \pm 0.11$ & $<0.001$ & $0.73 \pm 0.10$ & $1.41 \pm 0.15$ \\
\hline
\end{tabular}

Table 6 Interobserver and intraobserver variability

\begin{tabular}{lccc}
\hline Third & $\begin{array}{c}\text { Interobserver } \\
(N=20)\end{array}$ & $\begin{array}{c}\text { Intraobserver } \\
(N=20)\end{array}$ & $P$ \\
\hline $\begin{array}{l}\text { Percent change of } \\
\text { diaphragmatic thickness }\end{array}$ & $39.52 \pm 10.73$ & $39.54 \pm 10.76$ & 0.996 \\
Diaphragmatic excursion & $2.26 \pm 0.19$ & $2.26 \pm 0.19$ & 1.000 \\
Diaphragmatic slope & $1.48 \pm 0.12$ & $1.48 \pm 0.13$ & 0.967 \\
\hline
\end{tabular}

There were no statistically significant differences between interobserver and intraobserver sonographic measurements.

extubation leads to post-extubation respiratory failure that results in reintubation and accordingly poor outcome [12].

Many weaning parameters such as maximum inspiratory pressure [13], RSBI, minute ventilation, CROP index (dynamic compliance, respiratory rate, oxygenation, and maximum inspiratory pressure index) and tracheal airway occlusion pressure $0.1 \mathrm{~s}(P=0.1)$ had been used. Despite the use of these parameters, there are still errors in weaning assessment [14]. Diaphragm, the major muscle of inspiration, plays a critical role in the pathophysiology of respiratory failure [15]. Therefore, evaluation of the diaphragm function is crucial in patients subjected to weaning from MV [16]. Ultrasonography has emerged to evaluate diaphragm function and predict weaning outcome from MV [17].

Weaning success could be categorized as being simple or difficult. Simple weaning patient takes less than 1 week and only one trial to be weaned, while difficult weaning takes more than 1 week and more than three trials. On the other side, weaning failure was
Table 7 The receiver operating characteristic curve of percent change of diaphragmatic thickness

\begin{tabular}{lccc}
\hline & $\begin{array}{c}\text { Percent change } \\
\text { of diaphragmatic } \\
\text { thickness }\end{array}$ & $\begin{array}{c}\text { Diaphragmatic } \\
\text { excursion }\end{array}$ & $\begin{array}{c}\text { Diaphragmatic } \\
\text { slope }\end{array}$ \\
\hline $\begin{array}{l}\text { Cutoff } \\
\text { point }\end{array}$ & $30.105 \%$ & $1.84 \mathrm{~cm}$ & $0.94 \mathrm{~cm} / \mathrm{s}$ \\
$\begin{array}{l}\text { Area } \\
\text { under the } \\
\text { curve }\end{array}$ & 1.0 & 0.999 & 0.995 \\
$\begin{array}{l}\text { Sensitivity } \\
(\%)\end{array}$ & 100 & 100 & 100 \\
$\begin{array}{l}\text { Specificity } \\
(\%)\end{array}$ & 97.4 & 96.4 & 94.6 \\
$P$ value & $<0.001$ & $<0.001$ & $<0.001$ \\
\hline
\end{tabular}

considered as one of the following: nonscheduled extubation, need for reintubation, noninvasive positive pressure ventilation of the patient within $48 \mathrm{~h}$ after extubation, delayed extubation, and terminal extubation or tracheostomy.

Two hundred and forty (138 men and 102 women) invasively MV patients were chosen for our study, 117 (48.8\%) had successfully weaned from which 111 patients were with simple weaning and six patients were with difficult weaning, and $123(51.2 \%)$ patients had failed weaning from which 99 (41.2\%) patients were with terminal extubation, 12 patients with reventilation, seven patients with delayed extubation, and five patients were with tracheostomy.

Pirompanich and Romsaiyut [18] in their study assessed the role of diaphragm-thickening fraction and RSBI in weaning from MV. The recorded 25 (73.5\%) patients 
were successfully weaned and nine (26.5\%) patients failed weaning. This is because they conducted their study on 34 patients only, but we conducted our study on 240 patients which are relatively larger in number. Besides, we considered died patients (99) as part of the weaning failure as terminal extubation.

Weaning outcome was nearly matching with the weaning outcome of Luo et al. [19] with a difference in the number of studied patients between our study (240) and their study (60). They conducted their study on 60 patients assessing the role of diaphragm in weaning outcome by ultrasound in difficult-to-wean patients. There were 27 (45\%) patients who were successfully weaned and 33 (55\%) patients who failed weaning. From the failed group, 14 (23.3\%) patients had died.

Also, weaning outcome was different from the results of Samanta et al. [20] and Yoo et al. [12] in weaning outcome. Samanta et al. [20] conducted their study on 64 patients. There were 59 (92.2\%) patients with successful weaning and five $(7.8 \%)$ patients in failed weaning. Yoo et al. [12] conducted their study on 60 patients from which $47(78.3 \%)$ patients were successfully weaned and 13 (21.7\%) failed weaning. They assess patients only just before extubation and defined weaning failure as patients reventilated or need NIV within $48 \mathrm{~h}$ of extubation or need tracheostomy.

Weaning outcome in our study was affected by APACHE II score, ICU stay duration, and duration of using sedation. APACHE II score was significantly increased in the failed group; 24.65 compared to the successful group; 15.19 with, indicating more severity in the failed group (failed group and successful group). ICU stay significantly increased in the successful group, 7.00 days compared with the failed group; 5.77 days as the failed group included the dead patients as a terminal extubation and died early decreasing the ICU stay duration of the failed group. Duration of using sedation was statistically significantly higher in the failed group, $62.85 \mathrm{~h}$ (indicating prolonged mandatory ventilation) compared with the successful group, $30.37 \mathrm{~h}$. There was no statistical significance of ventilation duration in weaning outcome.

The final outcome (survived or died) is affected as well by the APACHE II score, ICU stay duration, and duration of using sedation. APACHE II score significantly increased in the died group; 24.13 compared with the survived group, 17.16, indicating more severity of disease in the died group. ICU stay duration was significantly high in the survived group; 6.73 days compared with the died group, 5.86 days. Duration of using sedation was statistically significantly higher in the died group, 62.75, indicating prolonged mandatory ventilation with decreased parameters values of successful weaning compared with the survived group, 35.96. There was no statistically significant effect of weaning duration and ventilation duration on the final outcome.

There was statistically significant difference of percent change of tdi between the first day of ventilation $(40.08 \%)$ and just before extubation (42.52\%) with $(P<0.001)$. Diaphragmatic excursion on the third day of ventilation was $1.72 \mathrm{~cm}( \pm 0.42)$ compared with the first day of ventilation $(1.78 \mathrm{~cm})$ with no statistical significance. In comparison to just before extubation, diaphragmatic excursion on the third day of ventilation was $2.19 \mathrm{~cm}$ compared with just before extubation $(2.21 \mathrm{~cm})$ with no statistical significance. There was statistically significant difference of diaphragmatic excursion between the first day of ventilation $(2.15 \mathrm{~cm})$ and just before extubation $(2.21 \mathrm{~cm})$.

There was a decrease in diaphragmatic slope on the third day of ventilation compared with the first day of ventilation and just before extubation with statistical significance between the first day of ventilation and just before extubation, and the third day of ventilation and just before extubation dissimilar between first and third day of ventilation that showed no statistical significant differences. This is matched with Goligher et al. [21] in their study which was conducted on $107 \mathrm{MV}$ patients with 10 nonventilated ICU patients. They found that over the first week of ventilation, diaphragm thickness decreased by more than $10 \%$ in $44 \%$ patients, was unchanged in $44 \%$ patients, and increased by more than $10 \%$ in $12 \%$ patients, and diaphragmatic contractile activity decreased with increasing ventilator driving pressure and controlled ventilator modes, and thickness did not vary over time following extubation or in nonventilated patients.

Along the course of ventilation, there was improvement in the sonographic measurements of diaphragm from the first day of ventilation, in which the patients are sedated and on mandatory ventilation (increased ventilator support) to just before extubation in which the patients are on spontaneous mode (no sedation, little, or no ventilator support). At the third day of ventilation, the sonographic measurements were decreased 
compared with the first day of ventilation and just before extubation. This may be related to the effect of MV, sedation, and initial pathology of the disease.

The sequential sonographic diaphragmatic measurements were statistically significantly higher in the successful compared with the failed group. As well as sonographic measurements were significantly increased in the survived compared with the died group. That may reflect the mandatory role of diaphragmatic muscle in weaning program and in endurance of respiratory system. This is consistent with Yoo et al. [12] who conducted their study on $60 \mathrm{MV}$ patients. They showed that patients had a greater tdi\% with the successful group; $42.1 \%$ compared with the failed group, $22.5 \%$ with $P$ value 0.03 .

In this study, the tdi $\%$, at cutoff point was $30.105 \%$, the sensitivity and specificity to predict weaning success were 100 and $97.4 \%$, respectively, with $P$ value less than 0.001 and area under the curve of 1.0 (Fig. 2). This is matched to Zambon et al. [22], Ferrari et al. [23], Baess et al. [24], Ali and Mohamad [25], Farghaly and Hasan [26], DiNino et al. [27] and Agamy et al. [28] in which the cutoff values of tdi\% associated with weaning success in their studies were 30-36, more than 36 , $30,30,30-36,30$, and more than $40 \%$, respectively. Ferrari et al. [23] concluded in their study that the sensitivity was $82 \%$ and the specificity was $88 \%$ while Baess et al. [24], recorded in their study 69\% sensitivity and $71 \%$ specificity. DiNino et al. [27] concluded in their study a sensitivity of $88 \%$ and a specificity of $71 \%$. Agmy et al. [28] referred in their study on 78 COPD patients in their exacerbation. They measure diaphragmatic thickening in the pressure support mode only with a sensitivity and specificity of 88 and $92 \%$, respectively.

The results were higher than that of Osman and Hashim [29], Pirompanich and Romsaiyut [18] and Samanta et al. [20]. Osman and Hashim [29] concluded that the cutoff value of tdi\% associated with weaning success in their study was $28 \%$ with a sensitivity and specificity of 88.9 and 100\%, respectively. Pirompanich and Romsaiyut [18] conducted their study on $34 \mathrm{MV}$ patients. The cutoff value of tdi\% that predict weaning success was $26 \%$ or more with a sensitivity of $96 \%$ and specificity of $68 \%$. Samanta et al. [20] conducted their study on $64 \mathrm{MV}$ patients. The cutoff value of tdi\% that predicts weaning success was $24.5 \%$ with a sensitivity of $97 \%$ and specificity of $81 \%$.

Regarding diaphragmatic excursion, diaphragmatic excursion of our studied patients in the successful group was $2.19 \mathrm{~cm}$ compared with the failed group, (1.38) with $P$ value less than 0.001 . These values were much more than others detected with Yoo et al. [12] who showed that diaphragmatic excursion in the successful group was $1.65 \mathrm{~cm}$ compared with the failed group, $0.8 \mathrm{~cm}$ with $P$ value less than 0.001 . At a cutoff point of $1.84 \mathrm{~cm}$ or more, the sensitivity and specificity of diaphragmatic excursion that predict weaning success were 100 and $96.4 \%$, respectively, with $P<0.001$ and area under the curve of 0.999 . This is different with most of the studies as Saeed et al. [30] who conducted their study on 50 COPD patients observed that the cutoff point of

Fig. 2
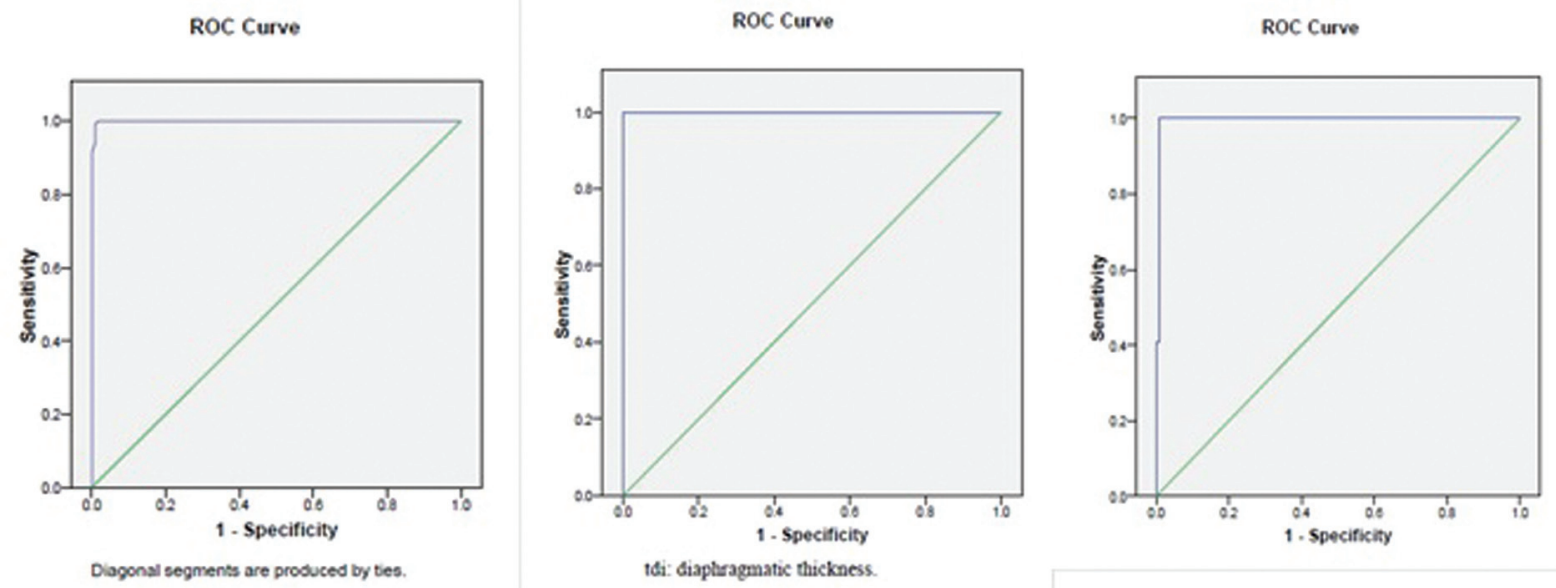

At a cutoff point of $30.105 \%$, the sensitivity and specificity of percent change of diaphragmatic thickness were 100 and $97.4 \%$, respectively. At a cutoff point of $1.84 \mathrm{~cm}$, the sensitivity and specificity of diaphragmatic excursion were 100 and $96.4 \%$, respectively. At a cutoff point of $0.94 \mathrm{~cm} / \mathrm{s}$, the sensitivity and specificity of the diaphragmatic slope were 100 and $94.6 \%$, respectively. 
diaphragmatic excursion associated with weaning success was $1.1 \mathrm{~cm}$ with a sensitivity of $86.4 \%$ and a specificity of 87.5\%. Osman and Hashim [29] showed that the cutoff value of diaphragmatic excursion that is associated with weaning success was $1.0 \mathrm{~cm}$ with a sensitivity and specificity of 83.3 and 100\%, respectively. Hayat et al. [31] conducted their study on $100 \mathrm{MV}$ patients. The cutoff value of weaning success was $1.2 \mathrm{~cm}$ with a sensitivity and specificity of 78.95 and $70.83 \%$, respectively. Zambon et al. [22] concluded in their systematic review study that cutoff values ranged from 1.0 to $1.4 \mathrm{~cm}$ predict weaning success. Baess et al. [24] showed that the cutoff point of diaphragmatic excursion that predicts weaning success was $1.0 \mathrm{~cm}$ or more with a sensitivity and specificity of 69.57 and 41.29\%, respectively. Ali and Mohamad [25] concluded that the cutoff value of diaphragmatic excursion associated with weaning success was $1.5 \mathrm{~cm}$ with a sensitivity and specificity of 88.7 and $84.3 \%$, respectively. Luo et al. [19] in their study which was conducted on 60 patients, the cutoff value of diaphragmatic excursion of weaning success was $1.2 \mathrm{~cm}$ with a sensitivity of $80 \%$ and specificity of $68.4 \%$. Matamis et al. [9] in which the cutoff value of diaphragmatic excursion was $1.8 \mathrm{~cm}$ or more which was associated with weaning success. Diaphragmatic slope in the successful group was $1.41 \mathrm{~cm} / \mathrm{s}$ compared with the failed group; $0.73 \mathrm{~cm} / \mathrm{s}$ with $P$ value less than 0.001 . At a cutoff point of $0.94 \mathrm{~cm} / \mathrm{s}$ or more that predicts the weaning success, the sensitivity and specificity of the diaphragmatic slope were 100 and $94.6 \%$, respectively, with $P$ value less than 0.001 and at an area under the curve of 0.995 . Matamis et al. [9] concluded in their study that the slope value which predicts weaning success was $1.3 \mathrm{~cm} /$ s $( \pm 0.4)$.

As regards complications, there were statistically significant higher complications; pneumothorax (2.1\%) and VAP (11.8\%) in the weak group with $P$ value 0.002 compared with the moderate; and in good function group there were no complications $(0.0 \%)$. We faced some limitations along the course of the study. First, poor image quality as we lost the cooperation and orientation of some MV patients. Second, difficulty in approaching the left hemi-diaphragm, especially in obese and those with splenectomy.

\section{Conclusion}

The measurement of tdi\% as well as excursion and slope could be applied in correlation more with weaning outcome with a sensitivity of $100 \%$ and specificity of $97.4 \%$.

\section{Financial support and sponsorship}

Nil.

\section{Conflicts of interest}

There are no conflicts of interest.

\section{References}

1 Caroleo S, Agnello F, Abdallah K, Santangelo E, Amantea B. Weaning from mechanical ventilation: an open issue. Minerva Anestesiol 2007; 73:417-427.

2 Vignon P, Repesse X, Vieillard-Baron A, Maury E. Critical care ultrasonography in acute respiratory failure. Crit Care 2016; 20:228.

3 Sigala I, Vassilakopoulos T. Diaphragmatic ultrasound as a monitoring tool in the intensive care unit. Ann Transl Med 2017; 5:79.

4 Rizk AM, Zidan MA, Emara DM, Abd El-Hady MA, Wahbi MO. Chest ultrasound in the assessment of patients in ICU: How can it help?. Egypt $J$ Radiol Nucl Med 2017; 48;313-322.

5 Mayo P, Arntfield R, Balik M. The ICM research agenda on critical care ultrasonography. Intensive Care Med 2017; 43:1257-1269.

6 Llamas-Alvarez AM, Tenza-Lozano EM, Latour-Perez J. Diaphragm and lung ultrasound to predict weaning outcome, systematic review and metaanalysis. Chest 2017; 152:1140-1150.

7 Bouhemad B, Brisson H, Le-Guen M, Arbelot C, Lu Q, Rouby JJ. Bedside ultrasound assessment of positive end expiratory pressure-induced lung recruitment. Am J Respir Crit Care Med 2011 183:341-347.

8 Dube BP, Dres M. Diaphragm dysfunction: diagnostic approaches and management strategies. J Clin Med 2016 5:113.

9 Matamis D, Soilemezi E, Tsagourias M, Akoumianaki E, Dimassi S, Boroli $\mathrm{F}$, et al. Sonographic evaluation of the diaphragm in critically ill patients: technique and clinical applications. Intensive Care Med 2013; 39:801-810.

10 Boles JM, Bion J, Connors A, Herridge M, Marsh B, Melot C. Weaning from mechanical ventilation. Eur Respir J 2007 29:1033-1056.

11 Mirzaei M, Pourmirza Kalhori R, Gh M, Khatoni A, Rezaei M. The effect of Riker sedation-agitation scale on clinical outcome of patients under coronary artery bypass graft surgery. Iran J Crit Care Nurs 2014; 6:223-228.

12 Yoo J, Lee SJ, Lee JD, Kim HC. Comparison of clinical utility between diaphragm excursion and thickening change using ultrasonography to predict extubation success. Korean J Intern Med 2018; 33:331-339.

13 Bien Udos S, Souza GF, Campos ES, Farah de Carvalho E, Fernandes MG, Santoro I. Maximum inspiratory pressure and rapid shallow breathing index as predictors of successful ventilator weaning. J Phys Ther Sci 2015; 27:3723-3727.

14 El-Khatib MF, Bou-Khalil P. Clinical review: liberation from mechanical ventilation. Crit Care 2008; 12:221.

15 Vivier E, Mekontso Dessap A, Dimassi S, Vargas F, Lyazidi A, Thille AW. Diaphragm ultrasonography to estimate the work of breathing during non invasive ventilation. Intensive Care Med 2012; 38:796-803.

16 McCool FD, Tzelepis GE. Dysfunction of the diaphragm. N Engl J Med 2012; 366:932-942.

17 Heunks LM, Doorduin J, van der Hoeven JG. Monitoring and preventing diaphragm injury. Curr Opin Crit Care 2015; 21:34-41.

18 Pirompanich $\mathrm{P}$, Romsaiyut $\mathrm{S}$. Use of diaphragm thickening fraction combined with rapid shallow breathing index for predicting success of weaning from mechanical ventilator in medical patients. $J$ Intensive Care 2018; 6:6.

19 Luo L, Li Y, Chen X, Sun B, Li W, Gu W. Different effects of cardiac and diaphragm function assessed by ultrasound on extubation outcomes in difficult-to-wean patients: a cohort study. BMC Pulm Med 2017; 17:161.

20 Samanta S, Singh RK, Baronia AK, Poddar B, Azim A, Gurjar M. Diaphragm thickening fraction to predict Weaning: a prospective exploratory study. J Intensive Care 2017; 5:62.

21 Goligher EC, Fan E, Herridge MS, Murray A, Vorona1 S, Brace D, et al. Evolution of diaphragm thickness during mechanical ventilation. Impact of inspiratory effort. Am J Respir Crit Care Med 2015; 192:1080-1088.

22 Zambon M, Greco M, Bocchino S, Cabrini L, Beccaria PF, Alberto Zangrillo A. Assessment of diaphragmatic dysfunction in the critically ill patient with ultrasound: a systematic review. Intensive Care Med 2017; 43:29-38. 
23 Ferrari G, De Filippi G, Elia F, Panero F, Volpicelli G, Aprà F. Diaphragm ultrasound as a new index of discontinuation from mechanical ventilation. Crit Ultrasound J 2014; 6:8.

24 Baess Al, Abdallah TH, Emara DM, Hassan M. Diaphragmatic ultrasound as a predictor of successful extubation from mechanical ventilation: thickness, displacement, or both? Egypt $J$ Bronchol 2016;162-166

25 Ali ER, Mohamad AM. Diaphragm ultrasound as a new functional and morphological index of outcome, prognosis and discontinuation from mechanical ventilation in critically ill patients and evaluating the possible protective indices against VIDD. Egypt $J$ Chest Dis Tubercu 2017; 66:339-351.

26 Farghaly S, Hasan AA. Diaphragm ultrasound as a new method to predict extubation outcome in mechanically ventilated patients. Aust Crit Care $2017 ; 30: 37-43$.
27 DiNino E, Gartman EJ, Sethi JM, McCool FD. Diaphragm ultrasound as a predictor of successful extubation from mechanical ventilation. Thorax 2014; 69:423-442.

28 Agmy G, Hamdy S, Farghally S. Diaphragm ultrasound as a novel guide of weaning from invasive ventilation. Eur Respir J 2015; 46:3264.

29 Osman AM, Hashim RM. Diaphragmatic and lung ultrasound application as new predictive indices for the weaning process in ICU patients. Egypt $J$ Radiol Nucl Med 2017; 48:61-66.

30 Saeed AM, El Assal GI, Ali TM, Hendawy MM. Role of ultrasound in assessment of diaphragmatic function in chronic obstructive pulmonary disease patients during weaning from mechanical ventilation. Egypt $J$ Bronchol 2016; 10:167-172.

31 Hayat A, Khan A, Khalil A, Asghar A. Diaphragmatic excursion: does it predict successful weaning from mechanical ventilation?. J Coll Physicians Surg Pak 2017; 27:743-746 